\title{
DISCUSSION
}

\section{Hydraulic conductivity of a recent estuarine silty clay at Bothkennar}

\author{
S. LEROUEIL, P. LERAT, D. W. HIGHT and J. J. M. POWELL (1992). \\ Géotechnique 42, No. 2, 275-288
}

\section{E. Juarez-Badillo, National University of Mexico}

The Paper contains good experimental data which help understanding of the hydraulic behaviour of soils and in obtaining the best parameters to characterize a given soil. I would like to present a general equation, given by the principle of natural proportionality, which can be applied to experimental permeabilities measured in the laboratory (Figs 6 and 9).

The natural equation provided by the principle of natural proportionality reads (Juarez-Badillo, 1983, 1992)

$$
\frac{k}{k_{1}}=\left(\frac{V}{V_{1}}\right)^{\kappa}=\left(\frac{1+e}{1+e_{1}}\right)^{\kappa}
$$

where $k$ is the permeability, $V$ is the total volume, $e$ is the nominal void ratio in terms of the initial volume of solids, $\kappa$ is a constant parameter-the coefficient of permeability, characteristic of the material and $\left(k_{1}, e_{1}\right)$ is a known point. The known point may be the in situ point $\left(k_{0}, e_{0}\right)$.

When a soil is one-dimensionally compressed its permeability anisotropy increases so that

$$
\begin{aligned}
& k_{\mathrm{v}}=k_{\mathrm{v} 1}\left(\frac{1+e}{1+e_{1}}\right)^{\kappa_{\mathrm{v}}} \\
& k_{\mathrm{h}}=k_{\mathrm{h} 1}\left(\frac{1+e}{1+e_{1}}\right)^{\kappa_{\mathrm{h}}} \\
& r_{\mathrm{k}}=\frac{k_{\mathrm{h} 1}}{k_{\mathrm{v} 1}}\left(\frac{1+e}{1+e_{1}}\right)^{-\left(\kappa_{\mathrm{v}}-\kappa_{\mathrm{h}}\right)}
\end{aligned}
$$

Equations (4)-(6) may alternatively be written as

$$
\begin{aligned}
& k_{\mathrm{v}}=k_{\mathrm{v} 0}(1+e)^{\kappa_{\mathrm{v}}} \\
& k_{\mathrm{h}}=k_{\mathrm{h} 0^{\prime}}(1+e)^{\kappa_{\mathrm{h}}} \\
& r_{\mathrm{k}}=\frac{k_{\mathrm{h} 0}^{\prime}}{k_{\mathrm{v} 0}{ }^{\prime}}(1+e)^{-\left(\kappa_{\mathrm{v}}-\kappa_{\mathrm{h}}\right)}
\end{aligned}
$$

where $k_{\mathrm{ho}}{ }^{\prime}$ and $k_{\mathrm{vo}}{ }^{\prime}$ are the permeabilities for the nominal (not the actual) void ratio $e_{1}=0$.

Equations (4)-(6) may also be written as

$$
\begin{aligned}
& k_{\mathrm{v}}=k_{\mathrm{ip}}\left(\frac{1+e}{1+e_{\mathrm{ip}}}\right)^{\kappa_{\mathrm{v}}} \\
& k_{\mathrm{h}}=k_{\mathrm{ip}}\left(\frac{1+e}{1+e_{\mathrm{ip}}}\right)^{\kappa_{\mathrm{h}}}
\end{aligned}
$$

$$
r_{\mathbf{k}}=\left(\frac{1+e}{1+e_{\mathrm{ip}}}\right)^{-\left(\kappa_{v}-\kappa_{\mathrm{h}}\right)}
$$

where $k_{\mathrm{ip}}$ is isotropic permeability for $e_{1}=e_{\mathrm{ip}}$ such that $r_{\mathrm{k}}=1$.

I believe that $e_{\mathrm{ip}}, k_{\mathrm{ip}}, k_{0}^{\prime}$, together with $\kappa_{\mathrm{v}}$ and $\kappa_{\mathrm{v}}-\kappa_{\mathrm{h}}$, may be used to characterize the permeability of soils.

By applying equations (4)-(12) to the experimental data presented in Figs 6 and 9 the results in Table 3 were obtained. The last column is the in situ value of $k_{0}$ from the equations (4)-(12); it compares well with the values of $k_{0}$ in Table 1 .

From $6 \mathrm{~m}$ to $15 \mathrm{~m}$ depth, $\kappa_{\mathrm{v}}$ varies from 5.5 to $7.6, \kappa_{\mathrm{h}}$ from 5.2 to 6.6 and $\kappa_{\mathrm{v}}-\kappa_{\mathrm{h}}$ from 0.5 to 1.5. Negative values of $\kappa_{\mathrm{v}}-\kappa_{\mathrm{h}}$ are unrealistic for a given soil sample. Values of $e_{\mathrm{ip}}, k_{\mathrm{ip}}$ and $r_{\mathrm{k} 0}$ that appear as unrepresentative of the clay deposit are written in parenthesis. When duplicated, values of $k_{0}{ }^{\prime}, \kappa$ and $\kappa_{\mathrm{y}}-\kappa_{\mathrm{h}}$ that appear representative are given in italics. It therefore appears that $\kappa_{v}$ varies from 6.7 to 7.6 . For the cases that are considered to be representative, the values of $k_{\mathrm{v} 0}$ 'vary from 0.26 to $0.82 \times 10^{-12} \mathrm{~m} / \mathrm{s}, e_{\mathrm{ip}}$ varies from 4.3 to $5.2, k_{\mathrm{ip}}$ varies from 0.91 to $3.6 \times 10^{-7} \mathrm{~m} / \mathrm{s}$ and the in situ permeability anisotropy $r_{\mathbf{k} 0}$ varies from 1.8 to $3 \cdot 1$, i.e. the clay deposit is very uniform.

Table 3 also shows the parameters I have found (Juarez-Badillo, 1991) for other soils; additional data are given in Juarez-Badillo (1983).

An important topic for futurc rescarch is the variation of all of these parameters as a function of the mineralogy, size, form, structure and activity of the solid particles and of the quality of water.

The relationship between the parameter $C_{\mathrm{k}}$ used by the Authors and $\kappa$ is

$$
C_{\mathrm{k}}=d e / d \log k=2 \cdot 3 k d e / d k
$$

Thus

$$
\frac{1}{k} \frac{d k}{d e}=\frac{2 \cdot 3}{C_{\mathbf{k}}}
$$

and, as

$$
\kappa=\frac{d k / k}{d e /(1+e)}=\frac{1+e}{k} \frac{d k}{d e}
$$


Table 3. Characteristics of laboratory permeability tests

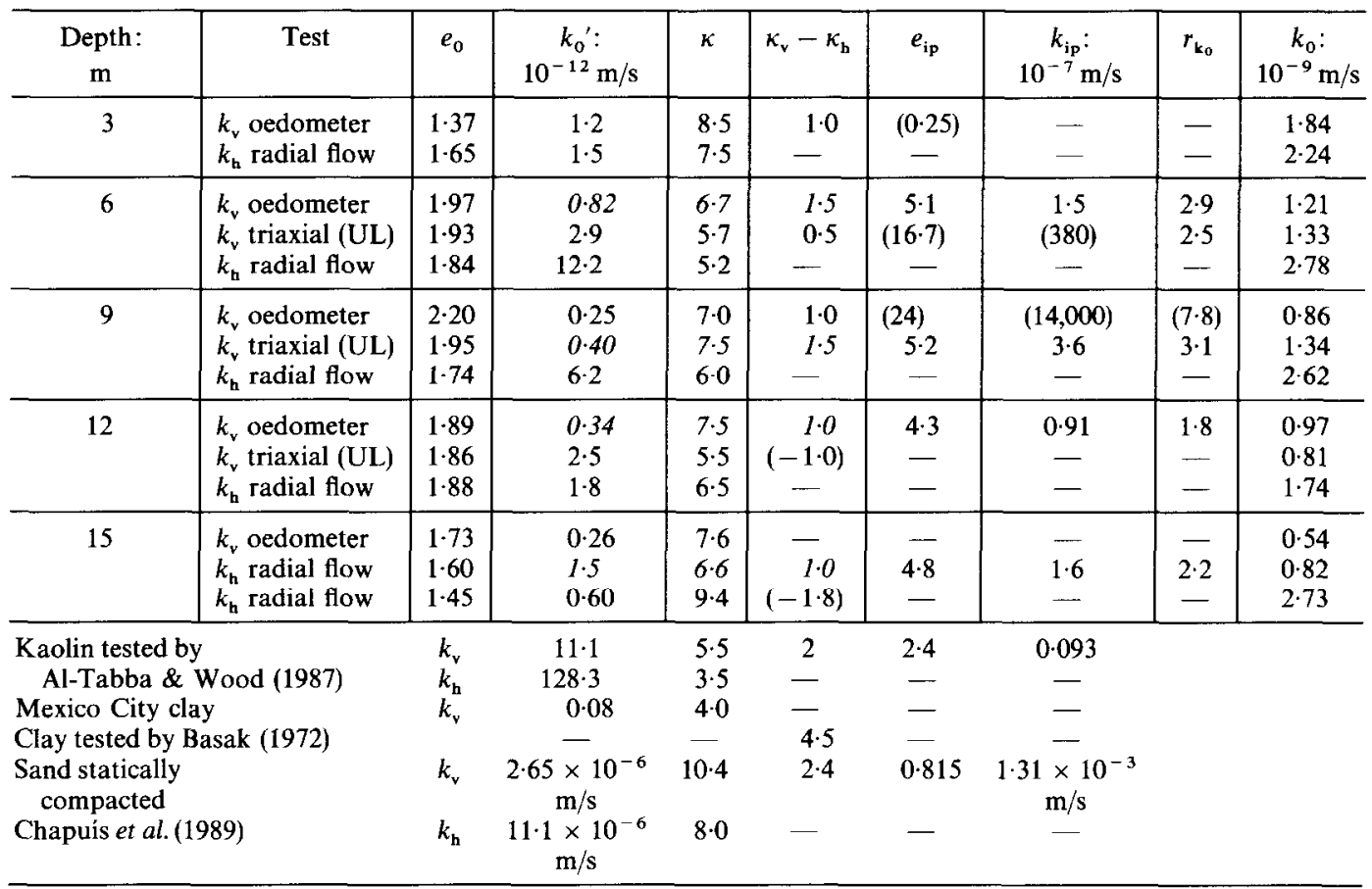

then

$$
\frac{1}{k} \frac{d k}{d e}=\frac{\kappa}{1+e}
$$

Comparing equations (14) and (16) gives

$$
C_{\mathrm{k}}=2 \cdot 3(1+e) / \kappa
$$

Equation (17) is very similar to the relationship between the compressibility index $C_{\mathrm{c}}$ and the coefficient of compressibility $\gamma$ (Juarez-Badillo, 1975)

$$
C_{\mathrm{c}}=2 \cdot 3 \gamma(1+e)
$$

The values of $C_{\mathrm{k}}$ and $C_{\mathrm{c}}$ decrease when the volume decreases and both tend to zero, as they should, when the volume tends to zero $(e=-1)$.

By taking $e_{0}=2$ and $\kappa_{v}=7$ with $\kappa_{\mathrm{h}}=6$, for this clay in the neighbourhood of $e_{0}$, equation (17) gives

$$
\begin{aligned}
& C_{\mathrm{kv}}=\frac{2 \cdot 3}{7}(1+2)=0.9857=0 \cdot 5 e_{0} \\
& C_{\mathrm{kh}}=\frac{2 \cdot 3}{6}(1+2)=1 \cdot 15=0 \cdot 58 e_{0}
\end{aligned}
$$

Equation (19) agrees with the equation quoted by the Authors. For large compressive strains, the variation of $C_{\mathrm{k}}$ may be taken into account by equation (17), i.e. $C_{\mathbf{k}}$ is directly proportional to $1+e$.

\section{REFERENCES}

Al-Tabba, A. \& Wood, D. M. (1987). Some measurements of the permeability of kaolin. Géotechnique 37, No. 4, 499-503.

Basak, P. (1972). Soil structure and its effects on hydraulic conductivity. Soil Sci. 114, No. 6, 417-422.

Chapuis, R. P., Gill, D. E. and Baass, K. (1989). Laboratory permeability tests on sand: influence of the compaction method on anisotropy Can. Geotech. J. 26, 614-622.

Juarez-Badillo, E. (1975). Constitutive relationships for soils. Proceedings of symposium on recent developments in the analysis of soil behaviour and their application to geotechnical structures, pp. 231-257. Kensington: University of New South Wales.

Juarez-Badillo, E. (1983). General permeability change equation for soils. Proceedings of international conference on constitutive laws for engineering materials, pp. 205-209. Tucson: University of Arizona.

Juarez-Badillo, E. (1991). Discussion on Laboratory permeability tests on sand: influence of the compaction method on anisotropy, by R. P. Chapuis et al. Can. Geotech. J. 28, 171-172.

Juarez-Badillo, E. (1992). Natural laws in geomechanics, pp. 31-36. Mexico: Sociedad Mexicana de mecánica de Suelos. 